\title{
Perancangan dan Realisasi Perangkat Keras Demodulator BPSK dengan Costas Loop
}

\author{
Budihardja Murtianta ${ }^{1}$, Deddy Susilo² ${ }^{2}$ Arivia Aurelia Devina ${ }^{3}$ \\ Program Studi Teknik Elektro, \\ Fakultas Teknik Elektronika dan Komputer, \\ Universitas Kristen Satya Wacana, Salatiga \\ 1 budihardja.murtianta@staff.uksw.edu, ${ }^{2}$ deddy.susilo@staff.uksw.edu, \\ ${ }^{3}$ me_230104@yahoo.com
}

\begin{abstract}
Ringkasan
Pada tulisan ini akan dirancang dan direalisasikan suatu perangkat demodulator data berbasis BPSK (Binary Phase Shift Keying) menggunakan metode Costas Loop. Costas Loop difungsikan untuk melakukan demodulasi sinyal-sinyal yang termodulasi secara supressedcarrier. Costas Loop menggunakan umpan balik negatif untuk melakukan carrier recovery, kemudian sinyal pembawa yang dihasilkan digunakan untuk melakukan demodulasi sinyal BPSK-nya. Perangkat yang dibuat berupa demodulator BPSK yang menggunakan format Non Return Zero Bipolar dengan frekuensi $10 \mathrm{kHz}-48 \mathrm{kHz}$. Untuk proses demodulasi BPSK harus dilakukan secara koheren[1]. Deteksi koheren adalah deteksi yang membutuhkan informasi fasa dan frekuensi asli dari sinyal pembawanya secara tepat[2]. Sehingga yang sering menjadi masalah pada deteksi koheren adalah bagaimana mendapatkan informasi tentang frekuensi dan fasa asli sinyal pembawa menggunakan sinyal pembawa yang telah termodulasi fasanya[3], proses ini sering disebut carrier recovery. Pada umumnya terdapat dua metode yang sering digunakan untuk carrier recovery pada deteksi koheren sinyal BPSK, yaitu Squaring Loop dan Costas Loop. Keduanya memiliki noise performance yang hampir sama [1], tapi metode Costas Loop memiliki toleransi yang lebih baik untuk pergeseran isyarat pembawa dan dapat beroperasi untuk lebar pita yang lebih lebar, sehingga lebih sering digunakan dibandingkan dengan Squaring Loop [4].
\end{abstract}

Kata kunci:Costas Loop, supressed-carrier, carrier recovery

\section{Pendahuluan}

Secara umum bagan kotak komunikasi digital digambarkan sebagai berikut.

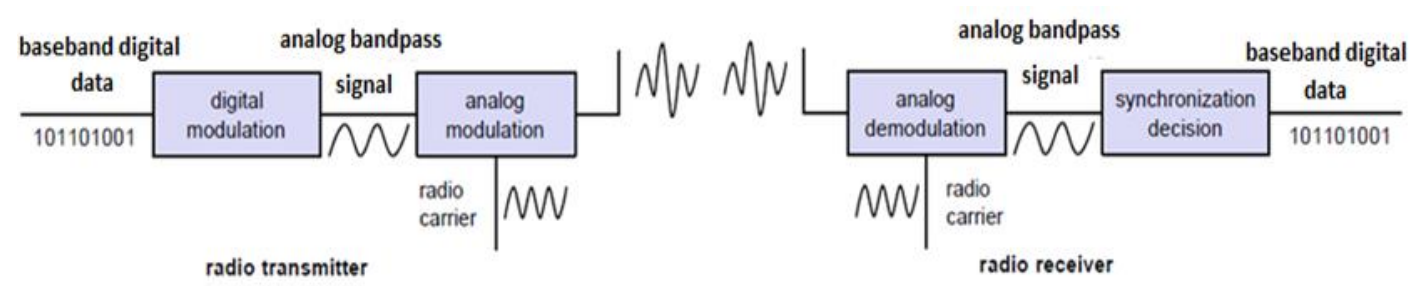

Gambar 1. Bagan Kotak Komunikasi Digital

Pada bagian pemancar, sinyal informasi digital baseband akan dimodulasikan dengan menggunakan modulator digital seperti modulator ASK, PSK atau FSK untuk menghasilkan keluaran yang disebut sinyal analog bandpass. Sinyal baseband didefinisikan 
sebagai sinyal yang memiliki magnitudo spektrum tidak nol untuk frekuensi disekitar $f=0$, sedangkan sinyal bandpass didefinsikan sebagai sinyal yang memiliki magnitude spektrum tidak nol pada pita tertentu dan terkonsentrasi pada frekuensi $f=f c$, dengan $f c$ adalah frekuensi pembawanya[1]. Sinyal analog bandpass ini masih memiliki frekuensi yang rendah dan tidak efektif untuk transmisi secara nirkabel, oleh karena itu sinyal analog bandpass ini perlu ditranslasikan ke frekuensi radio. Untuk mentranslasikan sinyal analog bandpass ke frekuensi radio dilakukan dengan menggunakan modulator analog. Sebagai modulator analog dapat digunakan modulator AM ataupun modulator FM. Proses pada bagian penerima adalah kebalikan dari bagian pemancar. Mula-mula sinyal frekuensi tinggi yang diterima oleh antena akan masuk ke demodulator analog untuk menghasilkan sinyal analog bandpass. Kemudian sinyal analog bandpass yang dihasilkan akan masuk ke bagian demodulator digital untuk menghasilkan sinyal informasi digitalnya. Rumusan teoretik mengenai modulator dan demodulator BPSK dengan metode costas loop sudah pernah dipublikasikan pada tulisan sebelumnya[5]. Pada tulisan ini direalisasikan rancangan perangkat keras pada bagian demodulator BPSK dengan metode Costas Loop.

\section{Demodulator BPSK}

Gambar 2 berikutini adalah bagan kotak dari suatu Costas Loop. Berdasarkan bagan kotak tersebut, maka perancangan bagian Costas Loop akan meliputi perancangan untai Pengali, Arm Filter, Loop Filter, VCO dan Penggeser Fasa $90^{\circ}$.

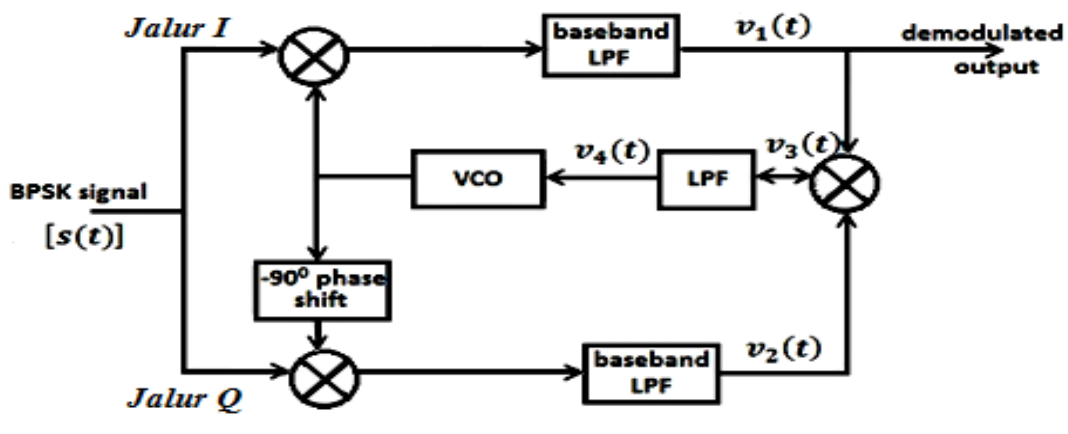

Gambar 2. Bagan KotakCostas Loop

\section{Untai Pengali}

Costas Loop menggunakan 3 pengali, 1 pengali di jalur Infasa, 1 pengali di jalur Quadrature dan 1 pengali di jalur tengah. Pengali di jalur Infasa dan Quadrature berfungsi sebagai detektor fasa, untuk mengetahui beda fasa antara sinyal keluaran VCO yang digeser $90^{\circ}$ (jalur Quadrature) dan yang tidak digeser $90^{\circ}$ (jalur Infasa) dengan sinyal BPSK masukan Costas Loop. Kemudian informasi beda fasa dari jalur Infasa dengan jalur Quadrature akan dikalikan oleh pengali di jalur tengah untuk menghasilkan tegangan pengontrol VCO.Pada perancangan bagian pengali akan ditetapkan terlebih dahulu bahwa sinyal BPSK masukan ke Costas Loop adalah sinyal sinusoida dengan amplitudo 2,5 Volt dan dinyatakan dengan persamaan berikut ini.

$$
s(t)=2,5 m(t) \sin \left(\omega_{c} t\right)
$$

Sedangkan keluaran dari VCO dan penggeser fasa adalah sinyal kotak dengan level tegangan TTL ( 0 Volt dan 5 Volt dan lewat kapasitor kopling akan dihasilkan sinyal 
kotak dengan amplitude 2,5Volt. Pada perancangan ini dipilih sinyal kotak sebagai keluaran VCO dan penggeser $90^{\circ}$, karena untuk mendapatkan pergeseran fasa $90^{\circ}$ pada jangkauan frekuensi tertentu lebih mudah didapat dengan menggunakan sinyal kotak yaitu menggunakan DFF (D-Flip Flop). Sinyal kotak yang digunakan memiliki amplitudo 2,5 Volt dan dapat dinyatakan dengan persamaan deret Fourier berikut ini.

$$
V_{V c o}(t)=10 / \pi \sin \left(\omega_{c} t+\theta_{-} e\right)+10 / 3 \pi \sin \left(3 \omega_{c} t+\theta_{e}\right)+10 / 5 \pi \sin \left(5 \omega_{c} t+\theta_{e}\right)
$$

Terlihat bahwa walaupun sinyal kotak yang digunakan memiliki banyak komponen frekuensi, tetapi dengan tapis pelewat rendah yang berpengaruh ke sistem hanya komponen frekuensi dasar $V_{V c o}(t)=10 / \pi \sin \left(\omega_{c t} t+\theta_{e}\right)$ yang sama dengan frekuensi pembawa BPSK-nya saja.

\subsection{PengaliJalur Infasa}

Pengali ini akan mengalikan sinyal BPSK dengan sinyal kotak keluaran VCO tanpa pergeseran $90^{\circ}$.

$$
\begin{gathered}
V_{\mathrm{o} 1}=K_{m 1} s(t) V(t) \\
V_{\mathrm{o} 1}=K_{m 1}\left(5 / 2 \sin \left(\omega_{c} t\right) m(t)\right)\left(10 / \pi \sin \left(\omega_{c} t+\theta_{e}\right)\right) \\
V_{o 1}=K_{m 1}(3.9789) m(t)\left(\cos \left(\theta_{e}\right)-\cos \left(2 \omega_{c} t+\theta_{e}\right)\right)
\end{gathered}
$$

$K_{m 1}$ adalah bati dari pengali.Informasi beda fasa diperoleh dari bagian frekuensi rendah, sedangkan bagian frekuensi tinggi akan dihilangkan dengan menggunakan tapis pelewat rendah. Sehingga keluaran dari pengali yang diharapkan adalah :

$$
V_{o 1}=K_{m 1}(3.9789) m(t) \cos \left(\theta_{e}\right)
$$

\subsection{Pengali Jalur Quadrature}

Pengali pada jalur Quadrature akan mengalikan sinyal BPSK dengan sinyal keluaran VCO yang telah digeser $90^{\circ}$.

$$
V_{02}=K_{m 2 S}(t) V_{V C O-90}(t)
$$

$K_{m 2}$ adalah bati dari pengali. Hasil pergeseran fasa $90^{\circ}$ nya dapat dinyatakan dengan Persamaan 7 berikut ini.

$$
V_{v C O-90}(t)=10 / \pi \cos \left(\omega_{c} t+\theta_{e}\right)
$$

Dengan menggunakan persamaan trigonometri dasar, maka akan didapatkan Persamaan 8 sebagai hasil dari perkalian sinyal BPSK dengan sinyal VCO yang digeser $90^{\circ}$ adalah.

$$
V_{o 2}(t)=K_{m 2}(3.9789) m(t)\left(\sin \left(\theta_{e}\right)+\sin \left(2 \omega_{c} t+\theta_{e}\right)\right)
$$

Keluaran pengali setelah dilewatkan tapis pelewat rendah sebagai berikut:

$$
V_{o 2}=K_{m 2}(3.9789) m(t) \sin \left(\theta_{e}\right)
$$

\subsection{Pengali Jalur Tengah}

Pengali di jalur tengah akan mengalikan hasil deteksi fasa di jalur Infasa dan Quadarature. Persamaan keluaran dari pengali ketiga adalah :

$$
V_{03}=K_{m 3} V_{01} V_{02}
$$

Dengan memasukkan Persamaan 4 dan 8 ke dalam Persamaan 10 dan memilih $K_{m 1}=$ $K_{m 2}=K_{m}$, maka akan didapatkan persamaan keluaran dari pengali ini adalah : 


$$
V_{o}(t)=K_{m 3}\left[K_{m} m(t)\right]^{2}(7,9) \sin \left[2\left(\theta_{e}\right)\right]
$$

Dengan menganggap $[m(t)]^{2}=1$, maka akan didapatkan persamaan :

$$
V_{o}(t)=K_{m 3}\left[K_{m}\right]^{2}(7,9) \sin \left[2\left(\theta_{e}\right)\right]
$$

Untuk merealisasikan suatu pengali digunakan IC MC1495 adalah Four QuadrantMultiplier dan realisasi pengali dengan menggunakan IC ini pada Gambar 3.

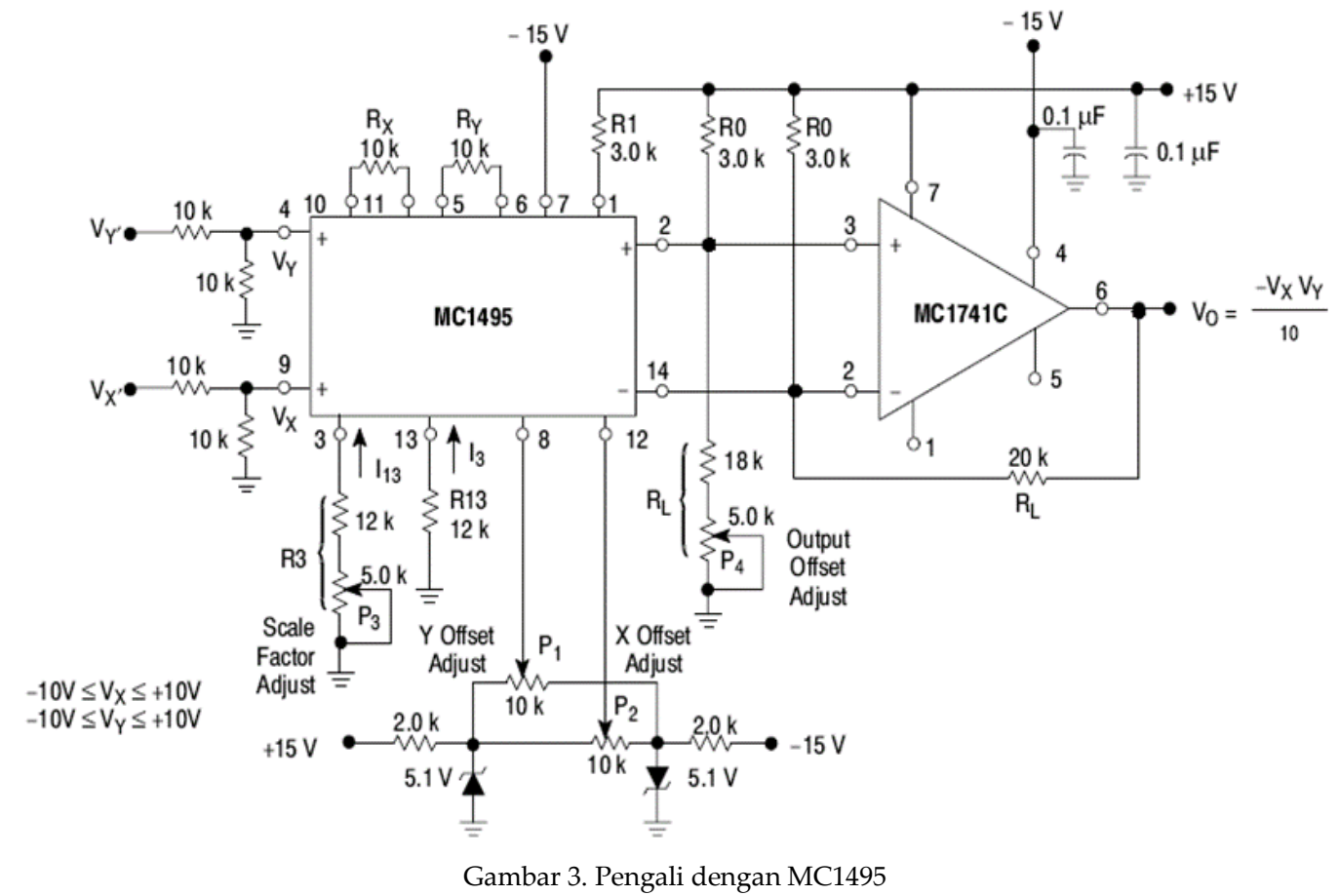

Keluaran dari MC 1495 adalah sinyal seimbang sehingga diperlukan untai penguat differential untuk mengubah sinyal balance menjadi unbalance. Untuk merealisasikan penguat differential digunakan suatu opamp LM741. Bati total untai pengali ini adalah 1/10. Untai pengali ini akan digunakan pada pengali di jalur Infasa, Quadrature dan jalur tengah. Untuk pengali di jalur Infasa dan Quadrature ditetapkan terlebih dahulu besarnya bati adalah $K_{m}=K_{m}=K_{m}=5 / 10$, sedangkan untuk pengali ketiga di jalur tengah, besarnya bati pengali ditetapkan sebesar $K_{m 3}=1 / 10$. Bati $5 / 10$ pada pengali jalur Infasa dan Quadrature diperoleh dengan menambahkan penguat opamp tak membalik dengan bati 5 kali setelah untai pengali. Suatu penguat opamp tak membalik dapat digambarkan seperti pada Gambar 4 dan besarnya bati penguat dapat dihitung dengan Persamaan 12 berikut ini.

$$
A v=1+R 2 / R 1=1+39 \mathrm{k} / 10 \mathrm{k}=4,9
$$

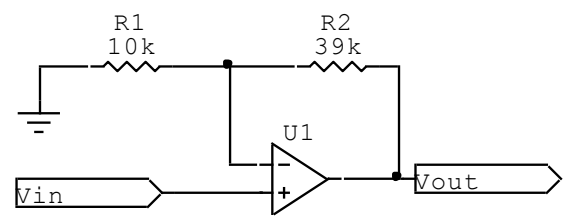

Gambar 4. Untai Penguat Opamp Tak Membalik

Keluaran pengali jalur Infasa: $V o 1=2 \cdot m(t) \cos \left(\theta_{e}\right)$. 
Keluaran pengali jalur Quadrature: $\operatorname{Vo2}=2 \cdot m(t) \sin \left(\theta_{e}\right)$.

Keluaran pengali jalur tengah : $V o(t)=0,2 \cdot \sin \left[2\left(\theta_{e}\right)\right]$

\subsection{Untai Arm Filter}

Arm Filter adalah tapis yang digunakan untuk meloloskan sinyal biner data dan menapis komponen sinyal frekuensi tinggi yang dihasilkan oleh pengali di jalur Infasa dan Quadrature. Untuk perancangan arm filter ada beberapa syarat yang perlu diperhatikan, yaitu :

1. Besarnya lebar pita dari arm filter harus mengikuti syarat $1 /(2 T s) \leq B W \leq 2 f c$ untuk meloloskan sinyal informasi dan mencegah ISI, dengan $T s$ adalah symbol rate[6,7,8]. Suatu sinyal kotak (pulsa) memiliki lebar pita yang tidak terbatas, tetapi pada transmisi sering kali diperlukan pembatasan lebar pita. Pembatasan pita ini sering kali terjadi karena disebabkan oleh pengaruh penapisan. Penapisan yang tidak tepat dapat menyebabkan bentuk pulsa menjadi melebar dalam ranah waktu dan mendistorsi simbol di sebelahnya, masalah ini yang disebut ISI. Gambar 3.18 menunjukkan contoh pulsa yang terdistorsi karena ISI.Berdasarkan syarat Nyquist, untuk melakukan transmisi 1/TBbit/sekon diperlukan lebar pita minimal sebesar $1 /(2 T B) \mathrm{Hz}$ untuk mencegah terjadinya ISI.

2. Arm filter di jalur Quadrature dan Infasa harus dibuat sama agar faktor tundaan antara sinyal $m(t) \sin (\theta e)$ dan $m(t) \cos (\theta e)$ sama[6].

Untuk merealisasikan suatu arm filter digunakan untai tapis lolos bawah Butterworth orde 2 dengan bati satu[6]. Karena kecepatan data maksimal yang digunakan adalah 9600 bps ( $T s=1 / 9600 \mathrm{~s}=10,417 \mathrm{~ms})$ dan frekuensi pembawa terendah adalah $10 \mathrm{kHz}$ maka diperlukan lebar pita arm filter sebesar $4800 \mathrm{~Hz} \leq \mathrm{BW} \leq 20000 \mathrm{~Hz}$. Berikut ini adalah untai tapis lolos bawah Butterworth orde 2 topologi Sallen-Key yang digunakan.

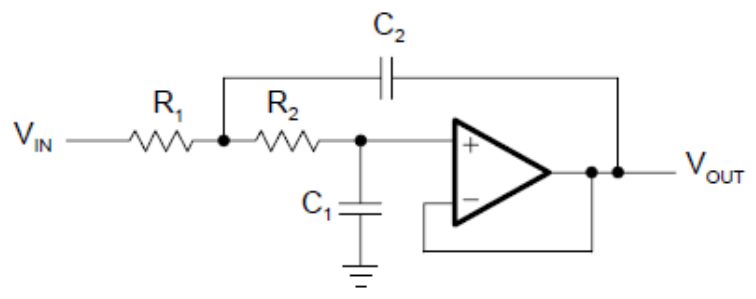

Gambar 5. Untai Arm Filter

Fungsi pindah dari untai tapis di atas dinyatakan dengan persamaan berikut ini.

$$
\begin{gathered}
A(s)=\frac{1}{1+\omega_{c} C_{1}\left(R_{1}+R_{2}\right) s+\omega_{c}{ }^{2} R_{1} R_{2} C_{1} C_{2} s^{2}} \\
R_{1,2}=\frac{a_{1} C_{2} \mp \sqrt{a_{1}{ }^{2} C_{2}{ }^{2}-4 b_{1} C_{1} C_{2}}}{4 \pi f_{c} C_{1} C_{2}} \\
a_{1}=\omega_{c} C_{1}\left(R_{1}+R_{2}\right) \text { dan } b_{1}=\omega_{c}{ }^{2} R_{1} R_{2} C_{1} C_{2} \\
C_{2} \geq C_{1} \frac{4 b_{1}}{a_{1}{ }^{2}}
\end{gathered}
$$

Dengan menggunakan Persamaan 14 dan 15, maka untuk mendapatkan frekuensi penggal sebesar $10000 \mathrm{~Hz}$, dapat dihitung nilai komponen-komponen yang digunakan adalah $C_{1}=150 \mathrm{pF}, C_{2}=470 \mathrm{pF}, R_{1}=30 \mathrm{k}$ dan $R_{2}=120 \mathrm{k}$. 


\subsection{Untai Loop Filter}

UntaiLoop Filter adalah tapis yang digunakan untuk mendapatkan informasi beda fasa, informasi beda fasa ini akan digunakan sebagai tegangan pengendaliVCO. Frekuensi keluaran VCO dipengaruhi oleh tegangan pengendali ini. Informasi beda fasa biasanya berupa sinyal dengan frekuensi rendah, oleh karena itu untai loop filter berupa tapis lolos bawah dengan bati DC yang tinggi. Tanggapan loop filter akan mempengaruhi tanggapan transient dari sistem, sehingga dalam perancangannya harus dilakukan dengan hati-hati. Beberapa hal harus diperhatikan untuk perancangan loop filter:

1. Dalam perancangan suatu demodulasi fasa diperlukan PLL dengan lebar pita yangkecil. Dengan lebar pita yang kecil akan menyebabkan fasa keluaran VCO $\theta_{0}$ tidak akan mengikuti modulasi fasa dan $\theta_{o}$ dapat dijadikan referensi untuk sinyal $\theta_{i}$ kemudian[6].

2. Agar sistem stabil, maka besarnya lebar pita dari PLL harus mengikuti persamaan berikut ini [6]:

$$
K \leq \omega L P / 4
$$

DenganK = lebar pita dari Costas Loop dan $\omega_{L P}=$ frekuensi penggal dari arm filter. Syarat ini bertujuan agar tanggapan frekuensi dari arm filter tidak mempengaruhi tanggapan frekuensi dari Costas Loop. Berdasarkan Persamaan 16 dan frekuensi penggal Arm Filter yang telah ditetapkan sebelumnya sebesar $10 \mathrm{kHz}$, maka lebar pita dari Costas Loop dapat dihitung $K \leq 2 \pi 10000 / 4$ atau $K \leq 5000 \pi$.

Untuk selanjutnya ditetapkan besarnya lebar pita dari Costas Loop adalah $K=5000 \mathrm{rad}$. Besarnya lebar pita Costas Loop K dinyatakan dengan persamaan 17.

$$
K_{d} K_{h} K_{o}
$$

Nilai konstanta-konstanta pada Costas Loop, yaitu meliputi :

1. Bati dari detektor fasa $K d=K m_{3}\left(K_{m} A_{i} A_{o}\right)^{2} / 4=(1 / 10)(5 / 10.5 / 2.10 / \pi)^{\wedge} 2 / 4=0.4 \mathrm{~V} / \mathrm{rad}$

2. Tetapan VCO $K_{0}=135.21 \times 10^{3} \mathrm{rad} / \mathrm{V}$ dan didapat dari pengujian VCO.

3. Bati frekuensi tinggi loop filter $K_{h}$

Berdasarkan persamaan 17, besarnya bati frekuensi tinggi Loop Filter $\mathrm{K}_{\mathrm{h}}$ dapat dihitung dengan cara :

$$
K_{h}=K /\left(K_{d} K_{o}\right)=5 /(135,21 \times 0,4)=0.092449
$$

Pada perancangan ini dipilih active lead-lag filter sebagai untai Loop Filter.

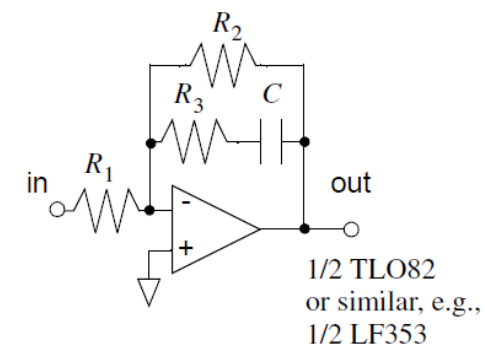

Gambar 6. Untai Active Lead-Lag Filter

Tapis pada Gambar 6 memiliki fungsi pindah yang dinyatakan dengan Persamaan 18 berikut ini.

$$
F(s)=K_{a}\left(1+s \tau_{2}\right) /\left(1+s \tau_{1}\right)
$$


Dengan $\tau_{2}=C R 3$ dan $\tau_{1}=C(R 2+R 3)$.

Untuk keperluan perancangan akan didefinisikan $K_{a}$ sebagai bati frekuensi rendah dari tapis dan dinyatakan dengan persamaan 19.

$$
K_{a}=\lim _{(s \rightarrow 0)} F(s)=R 2 / R 1
$$

Sedangkan untuk bati frekuensi tinggi dilambangkan dengan $K_{h}$ dan dinyatakan dengan persamaan 20 berikut.

$$
K_{h}=\lim _{(s \rightarrow \infty)} F(s)=(R 2 R 3) /(R 1(R 2+R 3))
$$

Tanggapan frekuensi dari tapis ini dapat digambarkan sebagai berikut.

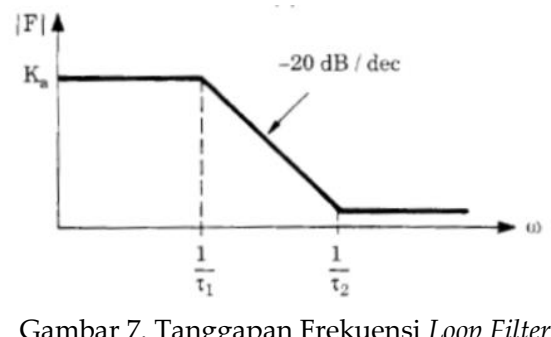

Agar pole $1 / \tau$ 2tidak mempengaruhi tanggapan sistem, maka disyaratkan $1 / \tau 2<K$. Pada perancangan biasanya dipilih $\omega_{2}=1 / \tau_{2}=1 / 4 K$, karena sistem akan memiliki overshoot yang cukup kecil dan acquisition yang cepat [6], sehingga akan didapatkan $1 / \tau_{2}=(1 / 4) K=1250$. Karena $\tau_{2}=\mathrm{CR} 3$ dan dipilih $C=100 \mathrm{nF}$, maka akan didapatkan $R 3=8000$ ohm.

Berdasarkan pengukuran karakteristik VCO, jangkauan tegangan masukan VCO yang diinginkan adalah -1 Volt sampai -4 Volt, dan frekuensi tengah operasional VCO yang diinginkan adalah -2,5Volt, sehingga diperlukan tegangan masukan VCO yang dapat berayun sebesar 1,5Volt. Keluaran dari pengali ketiga dinyatakan dengan persamaan $0.2 \sin \left(2 \theta_{e}\right.$ ) hanya memiliki ayunan tegangan sebesar $0,2 \mathrm{~V}$, oleh karena itu diperlukan penguatan agar ayunan sebesar 1,5 Volt dapat dicapai. Pada perancangan ini dipilih penguatan oleh bati frekuensi rendah KaLoop Filter sebesar 8 kali agar persyaratan ayunan itu terpenuhi.

$$
K_{a}=R_{2} / R_{1}=8
$$

Dengan menggabungkan persamaan di atas dengan persamaan bati frekuensi tinggi $K_{h}$ yang didapatkan sebelumnya, yaitu:

$$
K_{h}=\frac{R_{2} R_{3}}{R_{1}\left(R_{2}+R_{3}\right)}=0.092449
$$

Dapat dihitung nilai resistor $R 1=85,963 \mathrm{k}$ dan $R 2=687,7 \mathrm{k}$.

Besarnya damping ratio $\xi$ dinyatakan dengan persamaan 23 berikut.

$$
\xi=\frac{1}{2} \frac{K_{d} K_{a} K_{o} \tau_{2}+1}{\tau_{1}} \sqrt{\frac{\tau_{1}}{K_{d} K_{a} K_{O}}}
$$

Dengan memasukkan nilai $K_{d}, K_{a}, K_{o}, \tau_{1}$ dan $\tau_{2}$ dapat dicari damping ratio, yaitu $\xi=1.05$. Besarnya damping ratio dianggap optimum jika berada pada jangkauan $0,5 \leq \xi \leq 1$ [8]. 


\subsection{Rangkaian VCO dan Penggeser Fasa $90^{\circ}$}

VCO yang digunakan adalah suatu osilator gelombang kotak dengan level tegangan TTL. Gelombang kotak dipilih, karena lebih mudah mendapatkan pergeseran fasa $90^{\circ}$ pada jangkauan frekuensi tertentu, jika dibandingkan dengan gelombang sinus. VCO ini akan menghasilkan frekuensi 4 kali frekuensi pembawa BPSK yang dikehendaki $(4 f c)$. Keluaran dari VCO akan dilewatkan ke suatu susunan 2 buah DFF yang berfungsi sebagai pembagi frekuensi

$$
4 f_{c} \stackrel{\stackrel{\frac{1}{4}}{\rightarrow}}{\rightarrow} f_{c}
$$

sekaligus penggeser fasa $90^{\circ}$. Dengan cara ini dapat dihasilkan 2 sinyal kotak yang berbeda fasa $90^{\circ}$ secara tepat pada semua jangkauan frekuensi yang dikehendaki.Untuk merealisasikan untai VCO digunakan IC XR2206, seperti pada gambar berikut ini. IC ini dipilih karena mudah penggunaannya dan besarnya konstanta VCO $\left(K_{o}\right)$ dapat diatur dengan mudah menggunakan tambahan komponen eksternal.

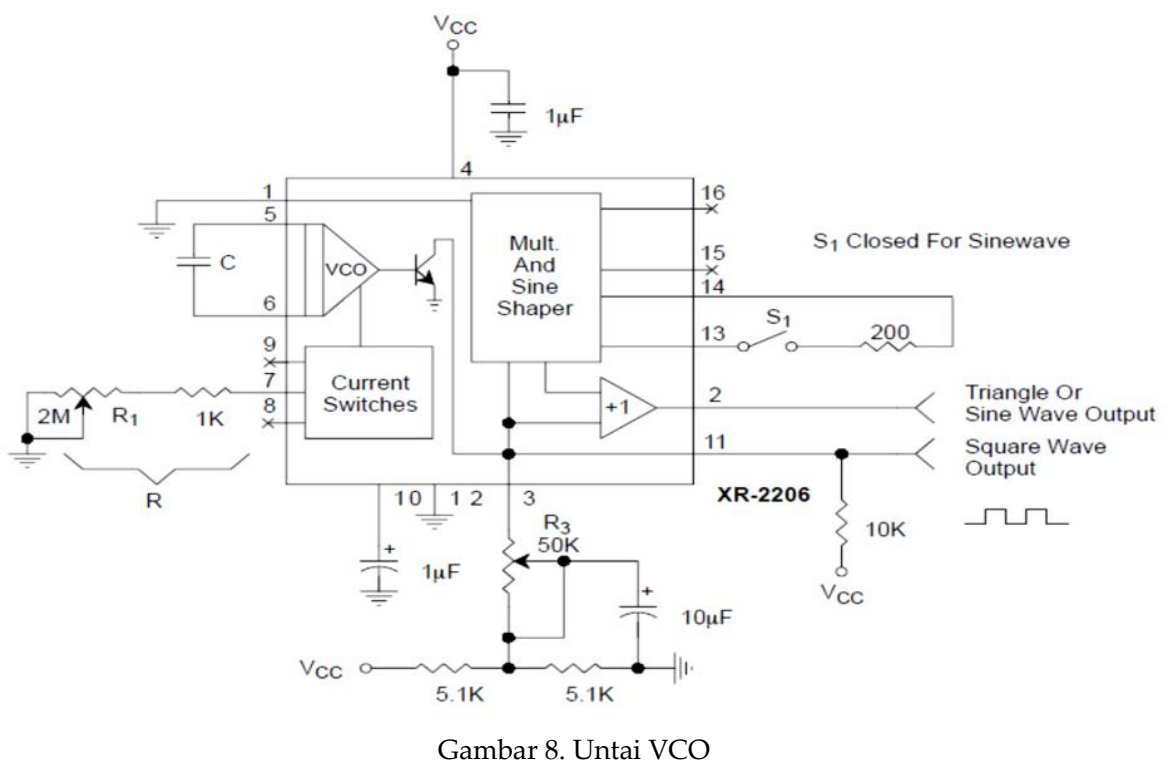

Frekuensi keluaran dapat diatur dengan memberi tegangan masukan pada pin 7 dan 8. Sedangkan untuk mengatur besarnya tetapan VCO (K_o) dilakukan dengan memberikan dua buah resistor di pin 7 atau 8, seperti dapat dilihat pada Gambar 9.

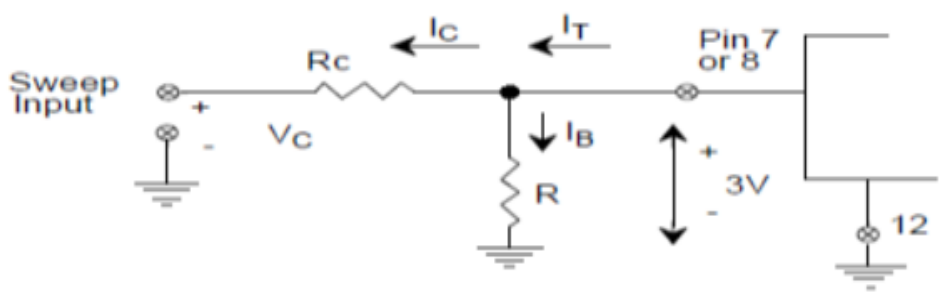

Gambar 9. Pengaturan tetapan VCO

Menurut data-sheet, besarnya frekuensi keluaran dari XR2206 dirumuskan :

$$
f=1 / R C+1 /(R c C)-1 /(3 R c C) V c
$$


Seperti telah dijelaskan sebelumnya, karena jangkauan alat yang dikehendaki adalah $10 \mathrm{kHz}-50 \mathrm{kHz}$, maka VCO harus mampu menghasilkan frekuensi 4 kalinya, yaitu pada jangkauan $40 \mathrm{kHz}-200 \mathrm{kHz}$. Pada tulisan ini dirancang agar VCO mampu menghasilkan keluaran dari frekuensi $30 \mathrm{KHz}-300 \mathrm{KHz}$. Agar dapat menghasilkan frekuensi keluaran seperti yang diharapkan, maka berdasarkan perhitungan didapatkan nilai komponen $R=8,2 \mathrm{k}, R c=3,6 \mathrm{k}$ dan $\mathrm{C}=1 \mathrm{nF}$.Berikut ini adalah grafik frekuensi keluaran $\mathrm{VCO}$ vs tegangan masukan $\mathrm{VCO}$ yang didapatkan dari pengujian.

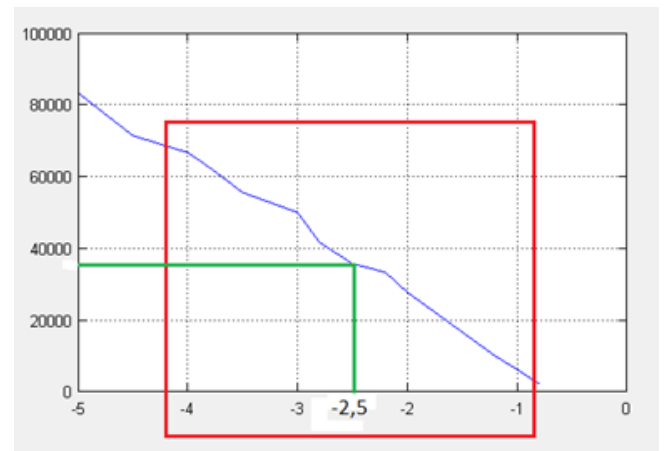

Gambar 10. Grafik frekuensi keluaran vs tegangan masukan VCO

Dari grafik tersebut, didapatkan konstanta VCO adalah

$$
K_{o}=-2 \pi \frac{27770-6250}{2-1}=-135.21 .10^{3} \mathrm{rad} / \text { Volt. }
$$

Dari grafik diatas terlihat juga bahwa tegangan operasi VCO yang diinginkan ada pada -4 Volt sampai -1 Volt, dan frekuensi tengah dari VCO adalah: Vin $=-2.5 \mathrm{~V}$, fout $=38,530 \mathrm{kHz}$. Agar Costas Loop (PLL) beroperasi pada frekuensi tengah dari VCO maka diperlukan suatu untai untuk mengatur frekuensi tengah operasional dari Costas Loop. Untai ini berupa suatu penguat differential yang akan mengurangkan tegangan masukan dengan tegangan referensi 2,5Volt. Untainya dapat dilihat pada Gambar 11 dan akan dipasang pada bagian masukan dari VCO.

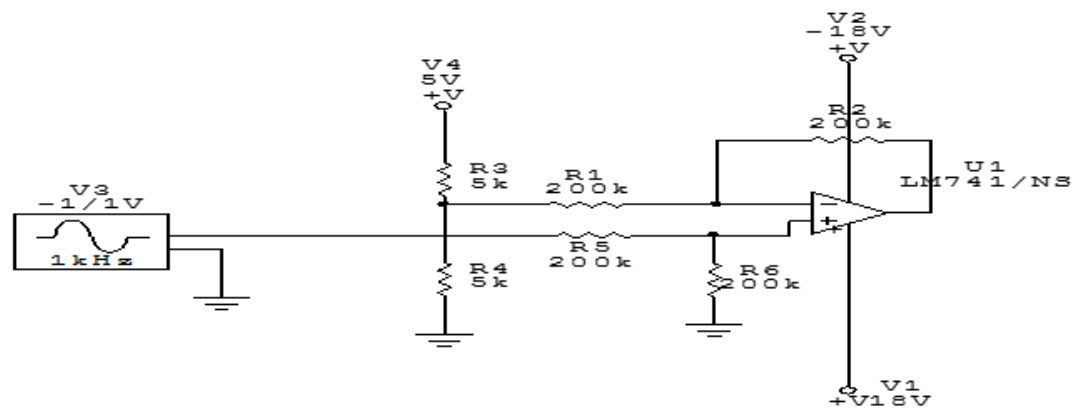

Gambar 11. Untai pengatur frekuensi tengah VCO

Penggeser fasa $90^{\circ}$ digunakan untuk mendapatkan dua buah sinyal yang berbeda fasa $90^{\circ}$. Untai ini juga digunakan untuk membagi 4 frekuensi keluaran VCO yang masih memiliki frekuensi $4 f c$. Untuk merealisasikannya, digunakan 2 buah DFF (D Flip-Flop) yang tersusun seperti pada Gambar 12 berikut ini. 


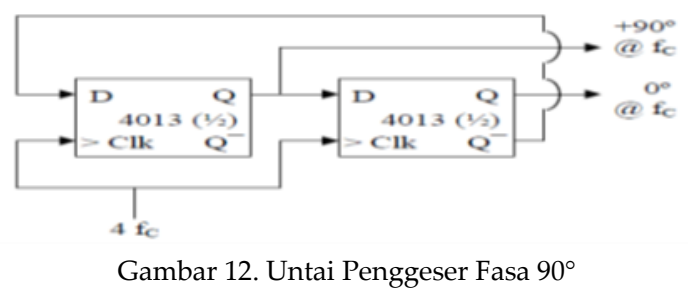

\subsection{RangkaianDecision Device}

Keluaran dari Costas Loop masih belum memiliki bentuk sinyal kotak yang sempurna, selain itu juga belum memiliki level tegangan TTL, sehingga belum dapat diolah secara digital. Oleh karena itu diperlukan untai tambahan untuk memperbaikinya. Untai ini disebut Decision Device. Untai decision device terdiri dari sebuah untai level shifter dan sebuah Schmitt trigger. Untai decision device berfungsi untuk mengubah sinyal keluaran Costas Loop yang masih berupa sinyal bipolar menjadi sinyal unipolar. Berdasarkan hasil pengujian, sinyal keluaran dari Costas Loop masih berupa sinyal bipolar dengan level tegangan $+1,58 \mathrm{~V}$ dan $-1 \mathrm{~V}$. Sinyal unipolar keluaran dari level shifter akan masuk ke bagian Schmitt trigger, untai ini digunakan untuk memperbaiki bentuk sinyal agar menjadi sinyal kotak dan mengembalikan level tegangannya menjadi level TTL. Untuk merealisasikan Schmitt trigger digunakan IC 7414. Gambar 13 berikut ini adalah realisasi dari untai Decision Device yang telah dibuat.

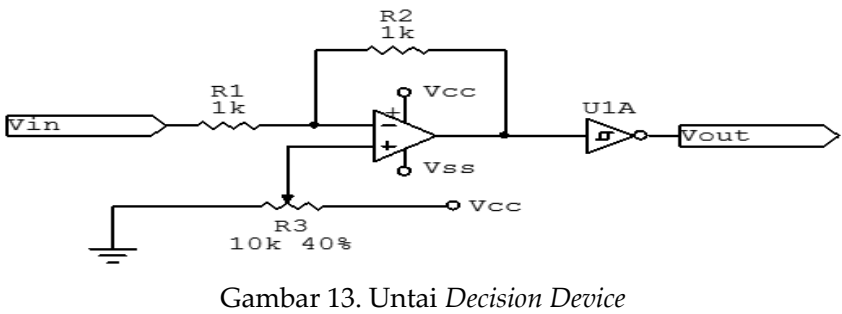

\section{Pengukuran dan Analisa}

\subsection{Pengujian Bagian Costas Loop}

Berikut ini adalah bagan kotak dari Costas Loop yang telah direalisasikan.

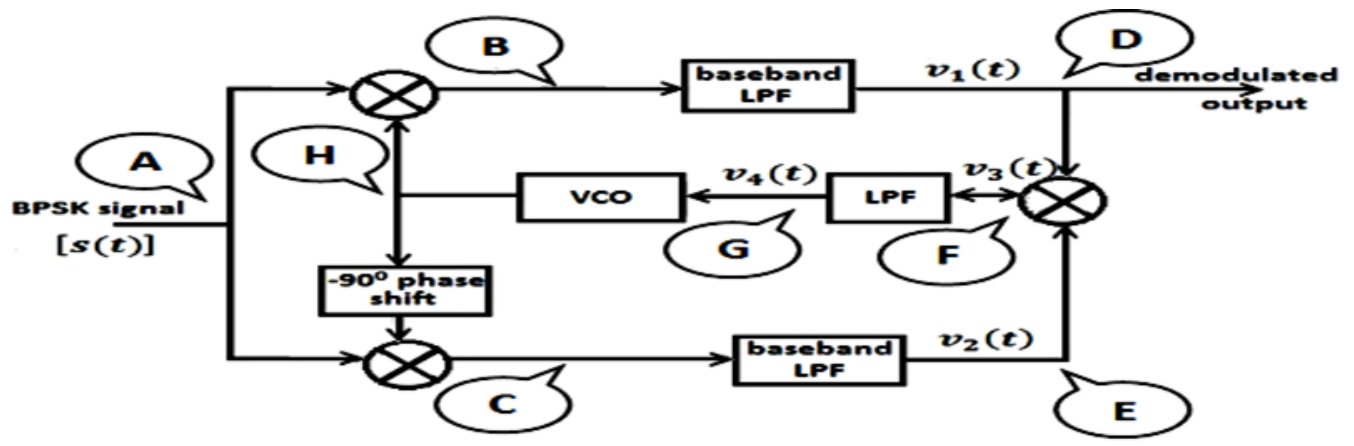

Gambar 14. Bagan Kotak Costas Loop dan Titik-titik Pengujiannya

\subsection{Pengujian VCO dan Penggeser $90^{\circ}$ (Titik $\mathrm{H}$ )}

VCO akan menghasilkan sinyal keluaran yang memiliki frekuensi sama dengan masukannya. Bagian VCO akan menghasilkan sinyal kotak dengan level TTL dengan 
frekuensi empat kali frekuensi pembawa BPSK-nya. Sinyal keluaran dari VCO kemudian akan dibagi 4 dengan untai DFF. Selain berguna untuk membagi 4 frekuensi keluaran dari VCO, untai DFF juga berguna untuk menghasilkan 2 buah sinyal kotak dengan beda fasa $90^{\circ}$ dan bentuk sinyal seperti terlihat pada Gambar 15a dan Gambar 15b.

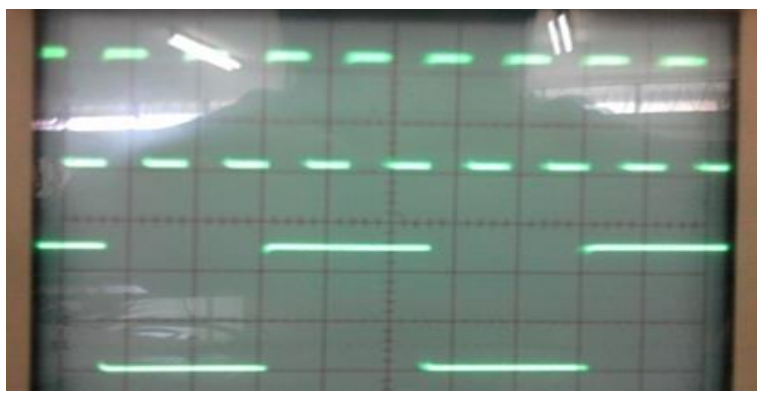

Gambar 15a. Gambar Atas : Sinyal Keluaran VCO \& Gambar Bawah : Sinyal Keluaran DFF

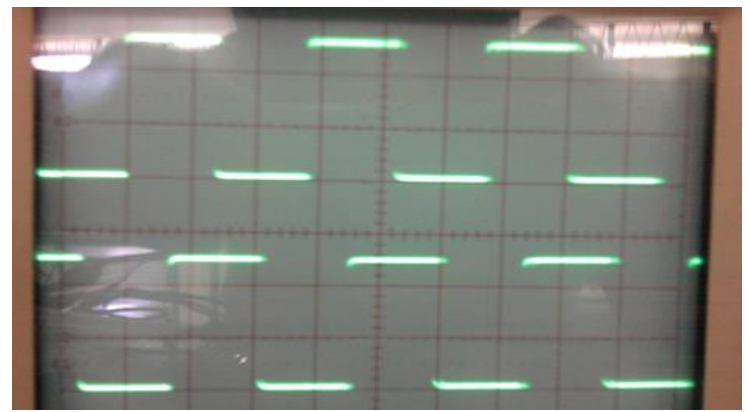

Gambar 15b. Penggeseran $90^{\circ}$ pada Kedua Keluaran DFF.

\subsection{Pengujian Pengali di Jalur Infasa dan Quadrature (Titik B dan C)}

Titik B dan C adalah keluaran dari pengali yang mengalikan sinyal kotak keluaran DFF dengan sinyal BPSK-nya. Berikut adalah hasil keluaran dari pengali tersebut.

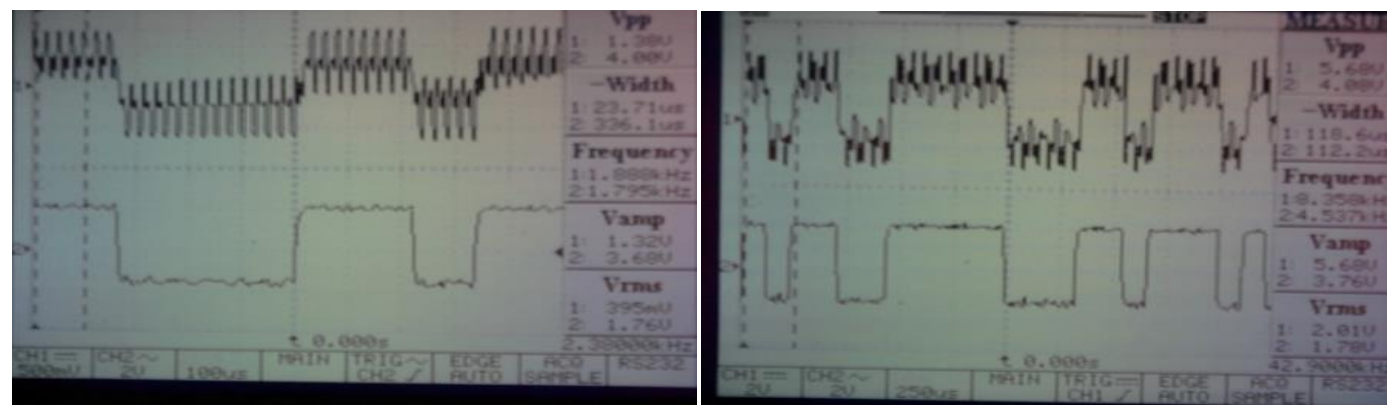

Gambar 16. (a) Keluaran Pengali Infasa(b) Keluaran Pengali Quadrature.Atas : keluaran pengali, Bawah : sinyal data digital

Perkalian sinyal BPSK dengan keluaran VCO dan penggeser $90^{\circ}$ menunjukkan pola data digital yang dikirimkan dan keluaran dari pengali jalur Infasa adalah:

$$
u_{d 1}(t)=K_{m I} \frac{A_{i} A_{o}}{2} m(t)-K_{m I} \frac{A_{i} A_{o}}{2} m(t) \cos \left(2 \omega_{i} t+\theta_{i}+\theta_{o}\right)
$$

Hasilnya diperoleh pada Gambar 16a, terlihat bahwa keluaran pengali memiliki pola sinyal informasinya dan juga komponen frekuensi tinggi.Sedangkan keluaran pengali untuk jalur Quadrature dinyatakan dengan persamaan :

$$
u_{d 2}(t)=K_{m Q} \frac{A_{i} A_{o}}{2} m(t) \sin \left(\theta_{i}-\theta_{o}\right)+K_{m Q} \frac{A_{i} A_{o}}{2} m(t) \sin \left(2 \omega_{i} t+\theta_{i}+\theta_{o}\right)
$$


Hasilnya diperoleh pada Gambar 16b dan dari tersebut terlihat bahwa amplitude komponen sinyal informasi lebih kecil daripada keluaran bagian Infasa. Hal ini terjadi karena saat loop dalam kondisi terkunci, maka $\theta_{i} \approx \theta_{0}$, sehingga $\sin \left(\theta_{i}-\theta_{0}\right)$ akan bernilai kecil, hal ini menyebabkan komponen sinyal informasi $K_{m} Q(A i A o) / 2 m(t) \sin \left(\theta_{i}-\theta_{0}\right)$ memiliki amplitudo lebih kecil.

\subsection{Pengujian Arm Filter di Jalur Infasa dan Quadrature (Titik D \& E)}

Keluaran dari bagian pengali di jalur Infasa dan Quadratiure masih memiliki sinyal dengan komponen frekuensi tinggi. Komponen frekuensi tinggi ini tidak dibutuhkan dan akan dihilangkan dengan arm filter. Gambar 17a dan $17 \mathrm{~b}$ adalah keluaran dari arm filter untuk jalur Infasa dan Quadrature dimana sinyal komponen frekuensi tinggi telah dihilangkan, sehingga didapatkan sinyal informasi aslinya.

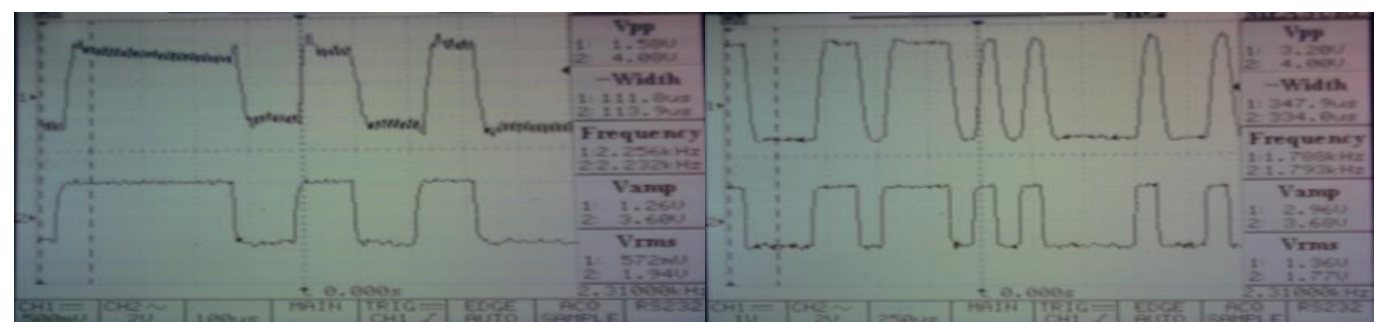

Gambar 17. (a) Keluaran Arm FilterInfasa (b) Keluaran Arm FilterQuadrature.Atas : Keluaran Arm Filter, Bawah : Sinyal data digital

\subsection{Pengujian Pengali Ketiga di Jalur Tengah (Titik F)}

Gambar 18. menunjukkan hasil pengujian dari keluaran pengali ketiga ini. Dapat dilihat bahwa saat keadaan terkunci besarnya keluaran dari pengali ketiga akan konstan pada $200 \mathrm{mV}$. Hasil ini disebabkan karena Costas Loop tidak beroperasi tepat di frekuensi tengah dari VCO. Frekuensi tengah dari VCO berdasarkan pengujian terletak di frekuensi sekitar $38,530 \mathrm{kHz}$, sedangkan frekuensi operasional Costas Loop yang digunakan dipilih $41 \mathrm{kHz}$.

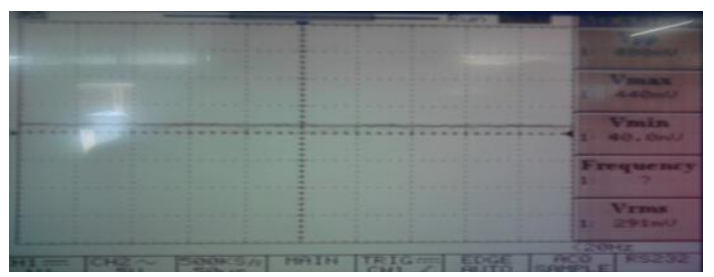

Gambar 18. Hasil Keluaran Pengali Ketiga

\subsection{Pengujian Loop Filter (Titik G)}

Loop Filterberguna untuk menghilangkan derau yang masih diloloskan, menghilangkan komponen frekuensi tinggi yang dihasilkan pada proses perkalian dan juga berfungsi sebagai penyedia tegangan pengontrol untuk VCO. Loop Filter ini berupa suatu tapis lolos bawah dengan bati DC yang tinggi. Gambar 19 berikut ini adalah keluaran Loop Filter yang didapatkan dari hasil pengujian, 


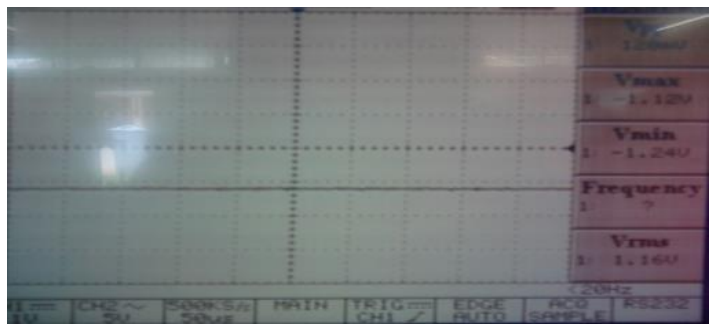

Gambar 19. Hasil Keluaran Loop Filter.

Pada kondisi terkunci, maka besarnya keluaran dari Loop Filter akan konstan pada nilai tertentu. Tegangan ini yang akan mengatur frekuensi keluaran pada VCO. Dari Gambar 19. terlihat bahwa tegangan keluaran Loop Filter konstan pada nilai -1,16Volt.

\subsection{Pengukuran Decision Device}

Seperti terlihat pada Gambar 20, keluaran dari Costas Loop sudah memiliki pola data digitalnya. Tetapi sinyal ini masih belum memiliki bentuk sinyal kotak yang sempurna dan masih belum memiliki level tegangan TTL, karena masih berupa sinyal bipolar. Untuk itu bagian decision device diperlukan untuk memperbaiki masalah ini.

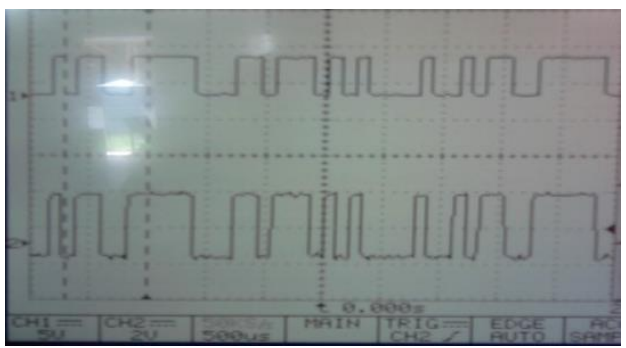

Gambar 20. Hasil Keluaran Decision Device.Atas : keluaran Decision Device, Bawah : sinyal data digital

Dari Gambar 20 terlihat bahwa keluaran decision device sudah berupa sinyal kotak sempurna dan sudah memiliki level tegangan TTL, sehingga bisa diolah lebih lanjut oleh perangkat-perangkat digital.

\section{Kesimpulan}

Costas Loopadalah variasi dari PLL agar dapat melakukan demodulasi sinyal-sinyal yang termodulasi secara supressed-carrier, dimana modulasi BPSK termasuk jenis modulasi supressed-carrier, contoh lainnya adalah modulasi AM-DSBSC.

Costas Loop yang telah direalisasikan sangat sensitif terhadap perubahan amplitudo sinyal BPSK yang masuk. Pada Costas Loop yang telah dirancang, sinyal masukan harus memiliki amplitudo 2,5Volt, jika ternyata amplitudo yang masuk lebih kecil atau lebih besar dari 2,5 Volt maka Costas Loop tidak akan terkunci atau data hasil demodulasinya salah.

Costas Loop yang dirancang memiliki hold range pada frekuensi 16,9 Khz - $66 \mathrm{KHz}$ dan lock range pada frekuensi $37,1 \mathrm{KHz}-49,7 \mathrm{KHz}$. Sebagai konsekuensinya agar Costas Loop dapat selalu terkunci, frekuensi pembawa BPSK-nya harus berada di dalam lock range-nya.

Salah satu kelemahan dari Costas Loop adalah 180 derajat fasa ambigu, dimana hal ini menyebabkan Costas Loop dapat terkunci pada fasa yang salah, yaitu sinyal dengan beda fasa 180 derajat dari sinyal yang seharusnya dikunci oleh Costas Loop. Hal ini 
menyebabkan data hasil demodulasinya berkebalikan dengan data aslinya. Fenomena ini dapat diatasi dengan menggunakan differential coding.

\section{Daftar Pustaka}

[1] L.W. Couch, Digital and Analog Communication System, 7rd ed, Pearson Education, Inc., New Delhi, 2007.

[2] B.P. Lathi,Modern Digital and Analog Communication System, Oxford University Press, Inc., New York, 1998.

[3] D.P. Feliciano, dan Rivera, L.C. Jose, Digital Implementation of a Second Order Costas Loop Demodulator, Project Report Electrical Engineering University of Puerto Rico, Mei 2004.

[4] D.R. Smith, Digital Transmision System, 3rd ed, Kluwer Academic Production, Massachussets, 2004.

[5] B. Murtianta, "Sistem Modulator dan Demodulator BPSK Dengan Costas Loop", Jurnal Techne, vol.14 no.1, pp. 17-26, Fakultas Teknik Jurusan Teknik Elektro Universitas Kristen Satya Wacana, ISSN : 1412-8292, April 2015.

[6] D.H. Wovaler, Phase-Locked Loop Circuit Design, Prantice-Hall, Inc., New Jersey, 1991.

[7] P. Chumchairat, dan P. Suwanna, A Costas Loop Circuit Design by Using Exclusive OR Gates Instead of Other Input Mixers Circuits, Departement of Electronics, Engineering Faculty King Mongkut's Institute of Technology Ladkrabang Chalongkrung Rd., Ladkrabang, Bangkok.

[8] J. Feign, Practical Costas Loop Design, www.rfdesign.com, 2002. 